\title{
Hans-Jochen Illiger 1939-2005 Wegbereiter für eine ganzheitliche Onkologie
}

Die internistische Onkologie hat sich in vielen kleinen Schritten quasi «aus dem Nichts» entwickelt, und HansJochen Illiger war von Anfang an aktiv dabei. Immer wieder half er, Therapien zu optimieren, Fehlentwicklungen zu erkennen und zu benennen, Erkanntes anzumahnen, Überholtes zu verlassen und Etabliertes zu sichern. Teamarbeit war ihm ein besonderes Anliegen: Ganzheitliche Krankenversorgung täglich zu praktizieren und sie interdisziplinär und interprofessionell zu stützen zeichnete seine klinische Arbeit aus. Illiger war einer der Wegbereiter für eine solide, nachvollziehbare Onkologie; sein wissenschaftlicher Schwerpunkt lag in der Versorgungsforschung, gegründet auf den Prinzipien der «good clinical practice».

Immer wieder geriet die onkologische Krankenversorgung auf Abwege. Für ihn besonders belastend waren berufspolitische Querelen, Eigennutz mal auf Seiten der Praxis- und mal von der Klinik-Onkologie. Diese Kontroversen zu überwinden war sein berufspolitisches Anliegen: Eine sinnvolle Arbeitsteilung zwischen ambulanter und stationärer Behandlung zu schaffen, die unterschiedlichen Tätigkeitsschwerpunkte in kommunalen Kliniken und onkologischen Schwerpunktpraxen zu sehen und hier wie dort auf optimale Qualität zu achten. So war er stets neutraler Mittler und als solcher anerkannt und immer wieder ein mit großen Mehrheiten gewählter Vertreter in berufspolitischen wie wissenschaftlichen Gesellschaften. Studentische Ausbildung, ärztliche Weiterbildung und berufsbegleitende Fortbildung wurden von ihm ein Berufsleben lang gefördert, höchsten internationalen Ansprüchen genügend. Auch war sein Engagement auf Seminaren, insbesondere für die von ihm begründete «Wilsede-Schule für Onkologie», sowie auf nationalen wie internationalen Kongressen wegbereitend und außerordentlich fruchtbar.

Sein vielfältiges persönliches, klinisches und wissenschaftliches Engagement für eine kompetente und umfassende onkologische Krankenversorgung ist und bleibt uns ein großes Vorbild. Seine nicht in den Vordergrund drängende Art und persönliche Bescheidenheit werden uns stets in Erinnerung bleiben. Wir trauern um einen kollegialen Freund, ein Vorbild und einen Wegbereiter für eine ganzheitliche Onkologie.

U. R. Kleeberg und H. J. Schmoll

\section{KARGER}

Fax +497614520714

E-mail Information@Karger.de

www.karger.com

(C) 2006 S. Karger GmbH, Freiburg 